\title{
The Knowledge, Attitude and Practices regarding HBV Infection of Married Women in the Reproductive Age Group living in different districts of Bangladesh .
}

\author{
Rahman $\mathrm{M} \mathrm{A}^{1}$, Mannan $\mathrm{S} \mathrm{R}^{2}$
}

\begin{abstract}
:
The present study was conducted to know the knowledge, attitude and practices of 300 married women in the reproductive age group living in different districts of Bangladesh, regarding $H B V$ infection. Only $20 \%$ of the women were found aware of the mode of transmission of $H B V$. However, $50 \%$ of the women were having the misconceptions regarding mode of transmission of $H B V .4 \%$ of women, $30 \%$ of children up to 5 years and $15 \%$ of children above 5 years were fully immunized with hepatitis $B$ vaccine. $80 \%$ of children up to 5 years and $75 \%$ of children above 5 years were fully immunized as per universal immunization programme. Hence, the results of the study clearly indicated the low immunization rate with vaccine against $H B V$ under universal immunization programme and this further potentiated the need to grow public awareness about vaccination against Hepatitis $B$ by focusing the beneficial effect of of early immunization through public electronic media.
\end{abstract}

Key words

$K A P, H B V$, Immunization, Perinatal transmission

\section{Introduction:}

Hepatitis-B (also known as 'serum" hepatitis) is an acute systemic infection with major pathology in the liver caused by (HBV) hepatitis-B virus ${ }^{1}$. Unlike in developed and several developing countries, hepatitis-B virus remains a major public health challenge in Bangladesh ${ }^{2}$. Its prevalence in Bangladesh and many other parts of the Asia pacific region is quite high. Bangladesh is situated in the intermediate prevalence region of hepatitis B virus(HBV). The lifetime risk of acquiring HBV infection in Bangladesh is greater than $40 \%$. It has been estimated that this virus is responsible for $10 \%-35 \%$ cases of acute viral hepatitis, $35.7 \%$ cases of fulminant hepatic failure, $33.3 \%-40.5 \%$ cases of chronic hepatitis and $46.8 \%$ cases of hepatocellular carcinoma in Bangladesh ${ }^{3}$. The life time risk of complications such as chronic hepatitis, cirrhosis and hepato-cellular carcinoma in subjects with chronic HBV infection is a major concern for health care personnel

1. Md.Atiqur Rahman1, Senior Lecturer, Department of Community Medicine, Anwer Khan Modern Medical College, Dhaka.

2. Sultana Rokeya Mannan, Associate Professor, Department of Physiology, Anwer Khan Modern Medical College, Dhaka today ${ }^{4}$. However, the outcome of HBV infection depends on the result of dynamic interaction between the virus, hepatocytes and host response. The HBV is present in high concentration in blood, serum, serus exudates, saliva, semen, vaginal fluid and most body fluids ${ }^{1}$. However, perinatal transmission is believed to be the most important mode in regions with intermediate and high HBV prevalence rates; in contrast the sexual transmission is the predominant route among adolescents in low prevalence and developed countries ${ }^{4}$. Moreover, most of the babies born to mothers who are carriers of HBV also become carriers. While keeping in view the magnitude of problem among children, it seems to be important to focus on the population of women of child bearing age and educate them regarding magnitude of the problem and its prevention. Moreover, there is a need for epidemiological studies to assess the knowledge, attitude and practices regarding HBV infection among women of child bearing age; so that steps would be taken to spread right knowledge among the target population and to efficiently tackle with the current problem. We conducted the present study to know the knowledge, attitude and practices of married women of the reproductive age group living in different districts of Bangladesh.

\section{Material and Methods}

The study was carried out in the Medicine Outpatient Department of "Sir Salimullah Medical College and Hospital" Mitford, Dhaka, Bangladesh. The study population consisted of 300 married women of the reproductive age group. Women attending medical out patient department of the Liver Center from July, 08 to July, 09 were randomly selected for the study (table 1). The females were interviewed after taking well informed consent. The questionnaire contained questions pertaining to identification data (name, age, religion, qualification, number of children under five year and above five year), knowledge (regarding transmission of HBV infection and source of information), attitude and practices regarding HBV infection. The questionnaire regarding mode of transmission contained the options like: physical contact, faeco-oral route, sexual contact, infected needle, blood transfusion, mosquito bite, social kissing, hugging and shaking hands. The attitude and practices regarding HBV infection of the women were tested by asking questionnaire 
about the preventive measures like use of safe water, use of condom, use of sterile needles, any drug addiction, use of tested blood and blood products and immunization practices. In addition to the above parameters subjects were also interviewed regarding self immunization against HBV and immunization of the children under universal immunization programme and with hepatitis $B$ vaccine. Subjects who had received all the doses of hepatitis B vaccine were considered as fully immunized, those who had received 1 or 2 doses of hepatitis $B$ vaccine were considered as partially immunized and those who had received no dose of hepatitis B vaccine were considered as un- immunized. Similarly children who had received all the doses of vaccines as per universal immunization programme (UIP) were considered as fully immunized; those who had missed one or more doses were considered as partially immunized and rest as un-immunized. At the end of the study all the data was collected and analysed for various parameters. Each parameter was expressed in percentage.

Table 1: Characteristics of the study population

\begin{tabular}{|l|c|}
\hline 1. Number of females & 300 \\
\hline 2. Age & $20-45$ yrs. \\
\hline 3. Number of children & 450 (average 1.5 per women) \\
\hline 4. Children under 5 yrs. & 300 \\
\hline 5. Children above 5 yrs. & 150 \\
\hline
\end{tabular}

\section{Results}

In the present study, out of total 300 women only $20 \%$ were aware of the mode of transmission of HBV and $50 \%$ of the women had misconceptions about mode of transmission like physical contact, faeco-oral route, mosquito bite, hugging and shaking hands (fig.1). Use of condoms and sterile needles was proposed by $20 \%$, avoidance of addiction by $50 \%$, immunization with hepatitis vaccine by $60 \%$ and use of safe water by $80 \%$ of the women as preventive measures against HBV infection (table 2). Among children under 5 years, $30 \%, 20 \%$ and $50 \%$ of the children were fully, partially and un-immunized respectively against HBV infection and in above 5 years group $10 \%, 20 \%$ and $70 \%$ of the children were fully, partially and un-immunized respectively against HBV infection (table 3). Moreover, $80 \%, 15 \%$ and $5 \%$ of the children were fully, partially and unimmunized respectively as per universal immunization programme in under 5 year group; whereas, $50 \%, 30 \%$ and $20 \%$ of the children were fully, partially and unimmunized respectively as per universal immunization programme in above 5 year group (table 3 ). Only $4 \%$ of the women were found to be fully immunized with hepatitis B vaccine and rest were un-immunized. Friends, radio, television, newspaper, doctor and magazines were found to be the source of information in $20 \%, 10 \%, 35 \%, 5 \%, 25 \%$ and $5 \%$ of the women respectively.
Fig. 1: Knowledge about mode of transmission of HBV infection among the study Population .

\section{Number of subjects}

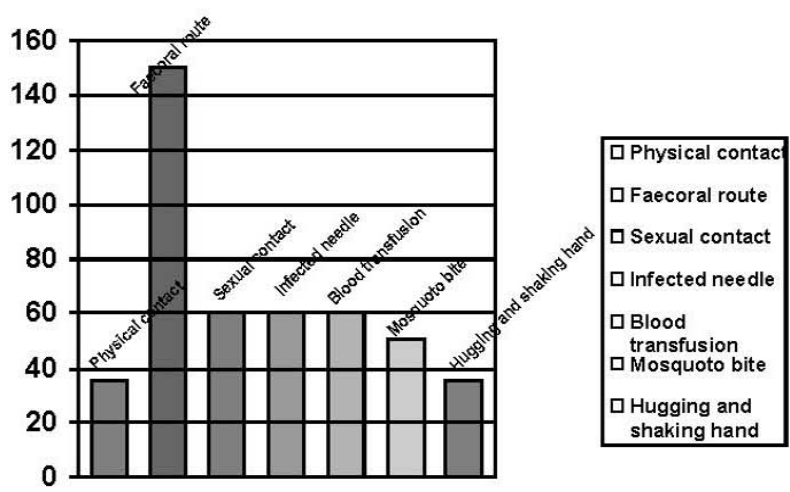

Table 2: Knowledge about preventive measures against HBV infection among the study population.

\begin{tabular}{|l|c|c|}
\hline Preventive measures & Yes: number=(n\%) & No: number=n(\%) \\
\hline Use of safe water & $240(80 \%)$ & $60(20 \%)$ \\
\hline Use of condom & $60(20 \%)$ & $240(80 \%)$ \\
\hline Use of sterile needles & $60(20 \%)$ & $240(80 \%)$ \\
\hline $\begin{array}{l}\text { Drug addiction } \\
\text { Use of tested blood and }\end{array}$ & $150(50 \%)$ & $150(50 \%)$ \\
\hline blood products & $112(27 \%)$ & $188(73 \%)$ \\
\hline Immunization practices & $180(60 \%)$ & $120(40 \%)$ \\
\hline
\end{tabular}

Fig. 2: Knowledge about preventive measures against HBV infection among the study population.

\section{Number of subjects}

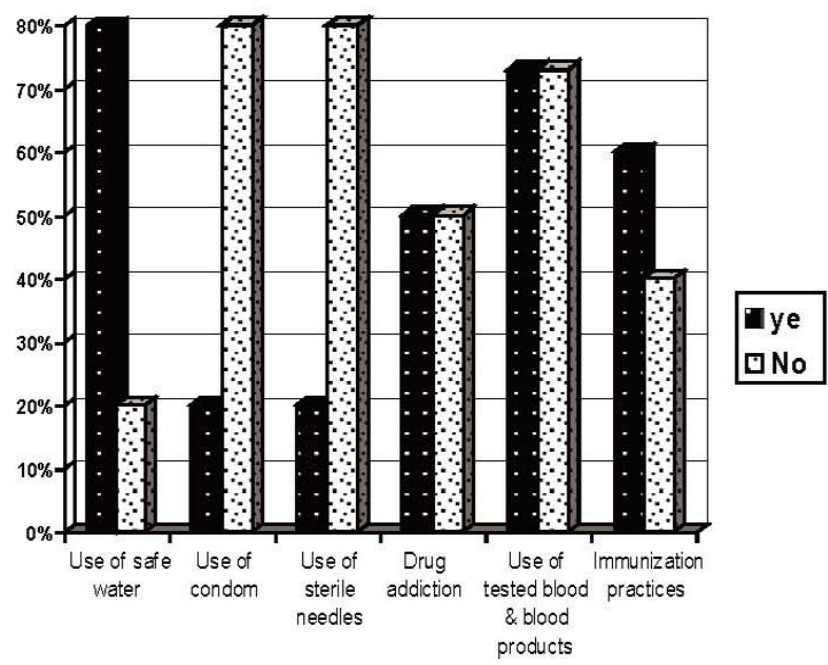


Table 3: Immunization status of children of women under study.

\begin{tabular}{|l|c|c|c|}
\hline $\begin{array}{c}\text { Immunization status } \\
\text { of children }\end{array}$ & Fully-n(\%) & Partially-n(\%) & Nill-n(\%) \\
\hline Under 5 yrs.(n=300) & & & \\
HBV & $90(30 \%)$ & $60(20 \%)$ & $150(50 \%)$ \\
UIP & $240(80 \%)$ & $45(15 \%)$ & $15(5 \%)$ \\
\hline More than 5 rs.(n=150) & & & \\
HBV & $15(10 \%)$ & $30(20 \%)$ & $105(70 \%)$ \\
UIP & $75(50 \%)$ & $45(30 \%)$ & $30(20 \%)$ \\
\hline
\end{tabular}

\section{Discussion}

HBV infection is caused by DNA virus with incubation period of 21-135 days (5). HBV infection kills about 1.1 million people globally every year (1). However, incidence of HBV infection could be brought down by giving proper education regarding its transmission and universal immunization of infants with hepatitis $B$ vaccine. In the present study only $20 \%$ of the women were aware about the mode of transmission of $\mathrm{HBV}$ and practicing preventive measures like use of condoms, sterile needles, not indulging in drug abuse and tested blood transfusion. Fifty percent of the women were having the misconceptions regarding mode of transmission of HBV infection like faeco-oral route, physical contact etc. Magnitude of awareness regarding HBV transmission in the present study was found to be quite lower than as reported for HIV (having similar mode of transmission) in a study conducted on teachers in Nepal (6). However, in another study conducted on barbers, majority were found ignorant regarding HIV transmission particularly through blade (7). Children below 7 years have the highest infection rates and most of the babies born to mothers who are carriers of HBV also become carriers(1). Moreover, carrier rate of $\mathrm{HBsAg}$ in pregnant women was reported as $3.1 \%$ (8). Therefore,immunization with hepatitis $B$ vaccine plays a very important role in controlling occurrence of HBV infection. But, only $4 \%$ of women, $30 \%$ of children up to 5 years and $15 \%$ of children above 5 years were fully immunized with hepatitis B vaccine respectively in our study population. $80 \%$ of children up to 5 years and $75 \%$ of children above 5 years were fully immunized as per UIP respectively. However, effective hepatitis B vaccine has been available since 2003. Routine infant immunization should be the primary strategy to prevent HBV infection globally. Universal vaccination is now proven to decrease the incidence of hepatocellular carcinoma (9).Universal immunization against HBV was started in USA in the year 1991 (10). Despite WHO recommendations for universal immunization against HBV infection by all countries by 1997, the policy has been implemented in Bangladesh since 2003 , but still now coverage is low . It may be due to lack of awarenwss about the beneficial effect of hepatitis $B$ vaccination. So, there is a paper recommendation for introducing Hepatitis B Vaccination awareness through the public electronic media.

\section{Conclusion}

While keeping in view the magnitude of problem it is important to focus on women of child bearing age and educate them regarding magnitude of the problem and its prevention. In our study, television was found to be the major source of information. So it is highly recommendable to utilize this source of information to spread education regarding prevention of the HBV infection.

\section{References:}

1. Ray SK. Vaccine preventable diseases. In. Chaturvedi $\mathrm{S}$, Jena TK eds. Epidemiology in maternal and child health, Preventive medicine. MME-101:IGNOU New Delhi 2003; 40-66.

2. Ganguly NK. Forward, prevention \& management of hepatitis B in Bangladesh-Current trends and future. Ind J Gasteroenterol 2000; 19 (3): 2.

3. Mamun-Al Mahtab, Salimur Rahman, Mobin Khan, Ayub Al Mamun and Md Fazal Karim, Viral load speaks little about toll on liver, (Hepatobiliary Pancreat Dis Int 2007; 6: 483-486)

4. Sarin SK, Singal AK. Preface: Prevention \& management of hepatitis B in India- the need for consensus. Ind J Gasteroenterology 2000; 19 (3): 1.

5. Sing H, Aggarval R, Singh RL, Naik SR, Naik S. Frequency of infection by HBV its surface mutants in a northern Indian population. Ind J Gasteroenterol 2003; 22: $132-37$.

6. Arnold S, Ronald JS. Hepatitis B. In. Hathaway WE, Hay WW, Jessie RG, John WP (eds). Current Pediatric Diagnosis and Treatment, edition.11 : New Delhi: Lange Medical Books/ Mc. Graw-Hill 1991; 620-23.

7. Jha N, Paudel IS, Chaturvedi S, Niraula SR. Teachers awareness and option about AIDS- A study from eastern Nepal. J Commun Dis 2001; 33(3): 205-11.

8. Khandait WD, Ambadekar NN, Vasudeo ND. Knowledge and ractices about HIV transmission among barbers of Nagpur city. Ind J Med ciences 1999; 53 : 167-71.

9. Datta SK, Gulati AK, Pandey LK, Pandey S. Hepatitis $B$ virus carriage in the pregnant women. J CommunDis 1988; 20(3): 209-12.

10. Chang MH, Chen CJ, Lai M S, Hsu HM, Wu TC, Kong MS et al. Taiwan childhood hepatoma study groupuniversal hepatitis B vaccination in Taiwan and the incidence of hepatocellular carcinoma in children. N EnglJ Med 1997; 336: 1855-59. 